\title{
Metformin inhibits growth and enhances radiation response of non-small cell lung cancer (NSCLC) through ATM and AMPK
}

\author{
Y Storozhuk ${ }^{1,2}$, S N Hopmans ${ }^{1}$, T Sanli ${ }^{1,3}$, C Barron ${ }^{4}$, E Tsiani ${ }^{4}$, J-C Cutz ${ }^{3}$, G Pond ${ }^{2}$, J Wright ${ }^{2,5}$, G Singh S $^{1,3}$ \\ and T Tsakiridis ${ }^{*}, 1,2,5$ \\ ${ }^{1}$ Department of Research, Juravinski Cancer Center, 699 Concession Street, Hamilton L8V 5C2, ON, Canada; ${ }^{2}$ Department of \\ Oncology, McMaster University, 1280 Main Street West, Hamilton, L8S 4LA, ON, Canada; ${ }^{3}$ Department of Pathology and \\ Molecular Medicine, McMaster University, 1280 Main Street West, Hamilton L8S 4LA, ON, Canada; ${ }^{4}$ Department of Community \\ Health Science, Brock University, 500 Glenridge Avenue, St. Catharines L2S 3A1, ON, Canada and ${ }^{5}$ Department of Radiation \\ Oncology, Juravinski Cancer Center, 699 Concession Street, Hamilton, L8V 5C2, ON, Canada
}

Background: We examined the potential of metformin (MET) to enhance non-small cell lung cancer (NSCLC) responses to ionising radiation (IR).

Methods: Human NSCLC cells, mouse embryonic fibroblasts from wild-type and AMP-activated kinase (AMPK) $\alpha 1 / 2$-subunit ${ }^{-1-}$ embryos (AMPK $\alpha 1 / 2^{-/-}-\mathrm{MEFs}$ ) and NSCLC tumours grafted into Balb/c-nude mice were treated with IR and MET and subjected to proliferation, clonogenic, immunoblotting, cell cycle and apoptosis assays and immunohistochemistry (IHC).

Results: Metformin (2.5 $\mu \mathrm{M}-5 \mathrm{~mm})$ inhibited proliferation and radio-sensitised NSCLC cells. Metformin (i) activated the ataxia telengiectasia-mutated (ATM)-AMPK-p53/p21 $1^{\text {cip } 1}$ and inhibited the Akt-mammalian target of rapamycin (mTOR)-elF4E-binding protein 1 (4EBP1) pathways, (ii) induced G1 cycle arrest and (iii) enhanced apoptosis. ATM inhibition blocked MET and IR activation of AMPK. Non-small cell lung cancer cells with inhibited AMPK and AMPK $\alpha 1 / 2^{-1-}-$ MEFs were resistant to the antiproliferative effects of MET and IR. Metformin or IR inhibited xenograft growth and combined treatment enhanced it further than each treatment alone. lonising radiation and MET induced (i) sustained activation of ATM-AMPK-p53/p21 cip1 and inhibition of AktmTOR-4EBP1 pathways in tumours, (ii) reduced expression of angiogenesis and (iii) enhanced expression of apoptosis markers.

Conclusion: Clinically achievable MET doses inhibit NSCLC cell and tumour growth and sensitise them to IR. Metformin and IR mediate their action through an ATM-AMPK-dependent pathway. Our results suggest that MET can be a clinically useful adjunct to radiotherapy in NSCLC.

Lung cancer (LC) is a leading cause of cancer mortality. More than $80 \%$ of LC patients are affected by non-small cell LC. Despite highdose radiotherapy in combination with chemotherapy, NSCLC shows poor local response (Curran, 2003), indicating a need for effective and well-tolerated adjuncts to radiotherapy.

Ionising radiation (IR) activates molecular pathways of tumour radioresistance, such as the protein kinase $\mathrm{B}$ (Akt) and mammalian target of rapamycin (mTOR) pathway (Bussink et al, 2008). These are effectors of tyrosine kinase receptors like EGF receptor (EGFR), which activates them through phosphatidylinositol 3-kinase (PI3k) and phosphoinositide-dependent kinase 1, an Akt-T308 kinase (Brachmann et al, 2009). Akt activates mTOR through (i) phosphorylation and inhibition of tuberous sclerosis complex 2 (TSC2), which inactivates the mTOR-activating GTP-binding protein Rheb, and/or (ii) phosphorylation of PRAS40 a member of mTORC1, one of the two functional complexes of mTOR, which includes mLST8/Gbl and the scaffold protein Raptor (Laplante and Sabatini, 2009). Mammalian target of rapamycin stimulates growth of cellular biomass, proliferation and resistance to cytotoxic agents (Petroulakis et al, 2006). It promotes gene expression and 
translation through phosphorylation-mediated activation of p70S6-kinase and phosphorylation-mediated inhibition of translation initiation inhibitor eIF4E-binding protein 1 (4EBP1; Petroulakis et al, 2006; Laplante and Sabatini, 2009).

Earlier, we showed that IR activates the energy sensor AMPactivated kinase (AMPK) pathway, a key, evolutionally preserved, kinase that mediates a metabolic cell cycle checkpoint (Sanli et al, 2010). AMPK is an effector of liver kinase B 1 (LKB1), a tumour suppressor mutated in Peutz-Jeghers syndrome, which is associated with breast and LC. AMP-activated kinase is a heterotrimeric enzyme of $\alpha$-, $\beta$ - and $\gamma$-subunits that senses low energy levels through AMP binding on the $\gamma$-subunit and is regulated by phosphorylation of the $\alpha$-subunit Thr172 (Steinberg and Kemp, 2009). AMP-activated kinase inhibits anabolic processes and protein synthesis by inhibiting mTORC1 through (i) Ser1387 phosphorylation and activation of TSC2, leading to enhanced Rheb GTPase activity and mTOR inhibition, or (ii) Raptor phosphorylation. AMPactivated kinase induces p53 and cyclin-dependent kinase inhibitors p2 $1^{\text {cip1 }}$ and p27 $7^{\text {kip1}}$, leading to cycle arrest (Gwinn et al, 2008; Mihaylova and Shaw, 2011). Our work suggested that AMPK is also a sensor of genomic stress. We suggested that IR activates AMPK acutely in epithelial cancer cell cultures to transduce signals through a DNA damage response (DDR)-mediated ataxia telengiectasiamutated (ATM)-AMPK-p53-p21 $1^{\text {cip1 }}$ axis, and mediate cell cycle arrest and radiosensitisation (Sanli et al, 2010).

Metformin (1-(diaminomethylidene)-3,3-dimethylguanidine) is a well-tolerated antidiabetic agent used by $>120$ million patients worldwide (Lord et al, 2003). Retrospective studies suggested that MET may decrease the risk of cancer in patients with type 2 diabetes (Evans et al, 2005; Bowker et al, 2006). Dowling et al (2007) showed that MET activates AMPK and inhibits mTOR, leading to inhibition of breast cancer cell proliferation (Dowling et al, 2007). This was prevented in cells lacking TSC2, LKB1 and cells exposed to the AMPK inhibitor compound $\mathrm{C}$, indicating that LKB1, AMPK and TSC2 are involved in the mechanism of MET action. Huang et al (2008) showed activation of the LKB1-AMPK pathway by MET and delay in tumour development in PTENdeficient mice (Huang et al, 2008). Reports suggest that MET can amplify chemotherapy-induced AMPK activation and enhances the cytotoxicity of chemotherapy in breast, lung and prostate cancer models (Iliopoulos et al, 2011; Rocha et al, 2011). Retrospective analysis suggested that MET may enhance chemotherapy responses in women with breast cancer (Jiralerspong et al, 2009). Currently, a randomised phase-III trial examines the potential of MET to reduce disease recurrence and improve survival in early-stage breast cancer patients after curative therapy (Goodwin et al, 2011).

In LC cells, we observed that MET enhances IR-induced activation of AMPK and clonogenic death (Sanli et al, 2010). Metformin is being investigated in a number of cancer sites (Goodwin et al, 2009; Goodwin et al, 2011; Taubes, 2012), but has not been examined in LC in combination with radiotherapy. Investigators remain concerned that most in vitro studies demonstrate antitumour activity at millimolar concentrations of MET, which are not clinically achievable (Dowling et al, 2012). The purpose of this study was to: (i) investigate the antiproliferative effects of clinically achievable low-dose MET in NSCLC models and to analyse the molecular pathways mediating its action and (ii) to examine whether MET can sensitise human NSCLC cells and tumours to IR.

\section{MATERIALS AND METHODS}

Antibodies and chemicals. Anti-CD31 antibody was purchased from Abcam (Cambridge, MA, USA) and all other antibodies were purchased from Cell Signalling Technology (Danver, MA, USA). Metformin HCL, rapamycin were obtained from Sigma-Aldrich
Canada (Oakville, ON, Canada). The ATM inhibitor KU60019 was obtained from Cedarlane Labs (Burlington, ON, Canada), and validated ATM and AMPK $\alpha 1 / 2$ siRNA were obtained from Qiagen Canada (Toronto, ON, Canada).

Cell culture. Human lung adenocarcinoma A549, H1299 and squamous cell carcinoma SK-MES1 cells were purchased from ATCC (Philadelphia, PA, USA) and cultured in RPMI 1640 media (10\% v/v foetal bovine serum (FBS); A549 and H1299) or DMEM media (5 mm glucose, 10\% FBS; SK-MES1). Wild-type (WT)-MEFs and AMPK $\alpha 1 / 2^{-/-}$-MEFs cells were kindly provided by Dr B Viollet, (INSERM, France).

Incubations. After overnight incubations, cells were treated with indicated doses of MET or rapamycin for $24 \mathrm{~h}$ before treatment with the indicated doses of IR. In KU60019 and siRNA experiments, cells were preincubated with those agents or vehicles $24 \mathrm{~h}$ and $72 \mathrm{~h}$, respectively, before incubation with or without MET for $48 \mathrm{~h}$ and/or treatment with IR $24 \mathrm{~h}$ later.

Proliferation assay. Cells were seeded $\left(1 \times 10^{3}\right.$ cells per well $)$ in 96-well plates in triplicates, were allowed to adhere overnight and subjected to treatments accordingly. After treatment, cells were washed with phosphate-buffered saline (PBS), fixed with methanol and stained with crystal violet dye. DNA content was quantified with BioTek Plate reader spectrophotometry software (BioTek, Winooski, VT, USA) at $570 \mathrm{~nm}$.

Clonogenic assays. Cells (500-1000) were seeded into 6-well plates in triplicate and maintained at the indicated doses of MET before IR $(0,2$ or $8 \mathrm{~Gy})$. After 7 days cells were fixed with methylene blue and viable colonies ( $>50$ cells) were counted. Data were fitted to the linear quadratic model using Graphpad Prism-5 software (GraphPad Prism Software Inc., La Jolla, CA, USA), as previously described (Sanli et al, 2011).

Cell cycle analysis. Cells were seeded at $1 \times 10^{6}$ cells per $\mathrm{ml}$ and left to incubate for $48 \mathrm{~h}$. Cells were treated with MET and IR for $24 \mathrm{~h}$ and $48 \mathrm{~h}$, respectively, were then washed in PBS, trypsinised, centrifuged at 1500 r.p.m., resuspended in $1 \mathrm{ml}$ of $95 \%$ ethanol and stored at $-20{ }^{\circ} \mathrm{C}$ for $24 \mathrm{~h}$. Then, they were centrifuged and resuspended in $1 \mathrm{ml}$ of propidium iodide staining solution, quantified with a FACS-calibur flow cytometry and the data were analysed using Expo32 ADC v1.1c software, Beckman-Coulter (Mississauga, ON, Canada).

Annexin-V assay. A549 cells $\left(5 \times 10^{5}\right)$ were seeded onto a glass coverslip and treated with MET and IR as indicated. Then cells were rinsed in PBS and stained using an annexin-V-EGFP apoptosis detection kit, as directed (Genscript, Piscataway, NJ, USA). The annexin V-EGFP antibody was visualised under a fluorescent microscope, as described (Mak et al, 2011).

$\gamma$ H2AX foci detection. A549 cells grown on glass coverslips were treated with MET or IR for the indicated times, washed, fixed using $3 \%$ paraformaldehyde and blocked in 5\% FBS/PBS/0.3\%-Triton-X100 . Cells were incubated with anti- $\gamma \mathrm{H} 2 \mathrm{AX}$-monoclonal antibody followed by an anti-mouse-Alexa-568-labelled secondary. $\gamma \mathrm{H} 2 \mathrm{AX}$ foci were detected using a fluorescent microscope, as described (Sanli et al, 2012b).

Xenograft model, treatments and tissue handling. Five-week-old $\mathrm{Balb} / \mathrm{c}$-nude mice (Charles-River, Mississauga, ON, Canada) were grafted with $1 \times 10^{6} \mathrm{~A} 549$ or H1299 cells by subcutaneous injection into the right flank. When tumour volume reached $100 \mathrm{~mm}^{3}$, animals were divided into: untreated (control), MET alone, IR or combined treatment (MET + IR). Tumour dimensions were measured by calliper every 5 days and volume was estimated as per: $V=$ length $\times$ width $\times$ height $\times 0.5236$. All experiments were approved by the McMaster University animal ethics board. Metformin treatment was delivered via drinking water at 
$300 \mathrm{mg} \mathrm{kg}^{-1}$ body weight per day till euthanasia. Water consumption was evaluated daily, MET intake was calculated and concentration in water was adjusted to achieve a daily intake of $300 \mathrm{mg} \mathrm{kg}^{-1}$. Ionising radiation treatments were delivered with a conformal technique (after dosimetric calculations and simulation) using clinical linear accelerators. Xenografts were subjected to either 0 or 10 Gy IR while animals were under gaseous anaesthesia housed inside high-efficiency particulate air filters (Sigma-Aldrich Co, LCC, Oakville, ON, Canada)-equipped Plexiglas tubes.

At euthanasia, extracted tumours were separated in two halves. One half was snap frozen in liquid nitrogen for later homogenisation, protein extraction and analysis by immunoblotting, and the other half was formalin-fixed (10\% solution for $24 \mathrm{~h})$ paraffinembedded for immunohistochemical analysis.

Immunoblotting and densitometry analysis. Twenty micrograms of protein from cell or xenograft lysates were subjected to $8-12 \%$ SDS-PAGE gels and transferred onto PVDF membranes, as described (Sanli et al, 2010). Immunoreactive bands were visualised with the ECL method and quantified using the Image J software (National Institute of Health (NIH), Bethesda, MD, USA). Band densities were first normalised for loading against the density of anti-actin immunoblots and then against the densities of untreated controls. For tumour lysates, for each marker-normalised average density values of bands belonging to the six control tumours were used as a master-control, against which all individual marker band densities were normalised.

Immunohistochemistry. Analysis was performed on $4-\mu$ m-thick formalin-fixed paraffin-embedded tumour sections as described earlier (Tsakiridis et al, 2008). Tissues were incubated with rabbit anti-P-AMPK (T172; $1: 200$ dilution), anti-CD31 (1:100 dilution) or anti-cleaved caspase 3 (CC3) $\left(1: 800\right.$ dilution) antibodies at $4{ }^{\circ} \mathrm{C}$ overnight, followed by incubation with Vector anti-rabbit biotinylated secondary antibody, Vector- $\mathrm{ABC}$ reagent (Vector Laboratories (Canada) Inc., Burlington, ON, Canada), diaminobenzidine substrate detection, wash, dehydration and mounting.

Statistical analysis. Paired $t$-test was utilised for statistical analysis of data between treatment groups for all experiments. Further, twoway ANOVA was used to compare treatment groups. Analysis was performed with SPSS software purchased by SPSS Inc. (Chicago, IL, USA), presently owned by IBM (Armonk, NY, USA). Statistical significance was determined as $P<0.05$. To determine whether the type of interaction between MET and IR was synergistic, additive or antagonistic, we used the combination index (CI) method of Chou and Talalay (1984) and the CompuSyn software (Combo Syn Inc., Paramus, NJ, USA). This method takes into account the potency (median dose or $\mathrm{IC}_{50}$ ) and the shape of the dose-effect curve (the $m$ value) to calculate the $\mathrm{CI}$ (Chou and Talalay, 1984; Chou, 2010). When the $\mathrm{CI}=1$ it indicates an additive effect; a $\mathrm{CI}<1$ indicates synergy and a $\mathrm{CI}>1$ indicates antagonism.

\section{RESULTS}

Metformin inhibits growth and sensitises cells to IR. To understand the time course of MET action, we analysed first A549 cells treated for $1-72 \mathrm{~h}$ with $5 \mu \mathrm{M}$ MET (Figure 1A). We observed evidence of AMPK phosphorylation (T172) within $4 \mathrm{~h}$, which reached high levels by $48-72 \mathrm{~h}$. For that, the majority of subsequent experiments with MET were performed with $48 \mathrm{~h}$ incubations, unless otherwise indicated.

A549, H1299 and SK-MES cells were subjected to treatments with MET alone and in combination with IR ( 2 or $8 \mathrm{~Gy}$; Figure $1 \mathrm{~B})$. At $5 \mu \mathrm{M}$, MET reduced significantly proliferation in all cell lines $(11 \pm 4.2 \%, 22 \pm 3.74 \%$ and $26 \pm 5.12 \%$ inhibition for A549, H1299 and SK-MES1 cells, respectively). Dose-dependent inhibition of proliferation was observed with $5 \mu \mathrm{M}-5 \mathrm{~mm}$ MET (up to $65-70 \%$ or $30-35 \%$ of control). Metformin inhibited proliferation further when combined with 2 or 8 Gy IR (Figure1B). Exact proliferation values with each MET and IR dose, the combinations and the incremental inhibition of proliferation by MET in irradiated cells is shown in Supplementary Data (Supplementary Table S1). To analyse the type of interaction between MET and IR, we used the Chou and Talalay (1984) method as described in Materials and Methods (Chou and Talay, 1984). We detected CI $<1 \quad(0.74-0.1)$ for all MET and IR combinations, indicating synergy between the two treatments in inhibiting NSCLC cell proliferation (see Supplementary Table S1).

As MET showed similar antiproliferative action in SK-MES and H1299 cells, we pursued the majority of subsequent experiments with A549 or H1299 cells. In clonogenic assays, MET $(5 \mu \mathrm{M}$ or higher) inhibited colony formation in A549 and H1299 cells (Figure 1C). H1299 cells showed greater sensitivity to MET with $32.0 \pm 2.6 \%$ inhibition of colony formation at $2.5 \mu \mathrm{M}$ MET and $54.4 \pm 1.7 \%$ inhibition at $5 \mu \mathrm{M}$, compared with $8.7 \pm 5.3$ and $38.2 \pm 8.4 \%$ for A549 cells. Next, we assessed the ability of MET (5 and $25 \mu \mathrm{M}$ ) to radiosensitise. Results were fitted into the linear quadratic model. Metformin (5 and $25 \mu \mathrm{M}$ ) radiosensitised cells indicated by the steeper slopes of the curves of MET-treated cells. This reached statistical significance $(P<0.05)$ at all IR doses at $25 \mu \mathrm{M}$ in both A549 and H1299 cells, and at $5 \mu \mathrm{M}$ in A549 cells treated with $8 \mathrm{~Gy}$ and $\mathrm{H} 1299$ cells treated with either 6 or $8 \mathrm{~Gy}$, compared with control cells treated with the same doses of IR but without MET (Figure 1C).

Comparison of MET with rapamycin. Metformin $(5-100 \mu \mathrm{M})$ inhibited proliferation to levels comparable to those achieved by widely used concentrations of rapamycin (5-25 nm; Figure 1D). Although rapamycin inhibited proliferation of non-irradiated cells further than MET, in irradiated cells the inhibition was similar with that of MET (5-100 $\mu \mathrm{M})$. A complete dose-response analysis of rapamycin in combination with IR is shown in Supplementary Data (Supplementary Figure S3). Both drugs exhibited parallel dose-dependent inhibition of proliferation in non-irradiated and irradiated cells.

Modulation of AMPK-p53 and mTOR pathways. Ionising radiation stimulated $\mathrm{AMPK}^{\mathrm{T} 172}$ phosphorylation and activity, marked by phosphorylation of its direct target acetylCoA carboxylase (ACC), in response to 8 Gy IR (Figure $2 \mathrm{~A}$ and $\mathrm{B}$ ). Similarly, IR increased total p53 and p $21^{\text {cip } 1}$ levels and enhanced p $53^{\text {Ser15 }}$ phosphorylation. No significant alterations in total and phosphorylated (T308 and S473) Akt levels or the total levels of mTOR were observed $24 \mathrm{~h}$ after IR, but we detected a trend for inhibition of $4 \mathrm{EBP} 1$ phosphorylation (by $34.3 \pm 14.3 \%$ ), indicating reduced mTOR activity (Figure $2 \mathrm{~A}-\mathrm{C}$ ).

Treatment with MET $(48 \mathrm{~h})$ and IR $(24 \mathrm{~h}$ after initiation of MET) phosphorylated AMPK $\alpha^{\text {T172 }}$. Metformin stimulated AMPK activity detected as enhanced ACC phosphorylation (at $100 \mu \mathrm{M}$ MET). The MET pretreatment potentiated IR induction of total and phosphorylated $\mathrm{p} 53$, but did not induce further $\mathrm{p} 21^{\mathrm{cip} 1}$ expression in these conditions (Figure 2A and B). Metformin $(5 \mu \mathrm{M})$ did not affect the levels of phosphorylated and total Akt, and showed minor trends for reduced total mTOR and phosphorylated 4EBP1. At $100 \mu \mathrm{M}$ MET, we did observe small but significant reductions of Akt-S473 phosphorylation, total mTOR and phosphorylated 4EBP1 levels. However, MET both at $5 \mu \mathrm{M}$ and $100 \mu \mathrm{M}$ mediated a robust inhibition of 4EPB1 phosphorylation in irradiated cells (Figure 2A and C). We postulate that the enhanced inhibition of $4 \mathrm{EBP} 1$ phosphorylation by MET in irradiated cells is the result of a potentiation of signalling events downstream of AMPK as a result of the combined IR and MET treatments. 
A

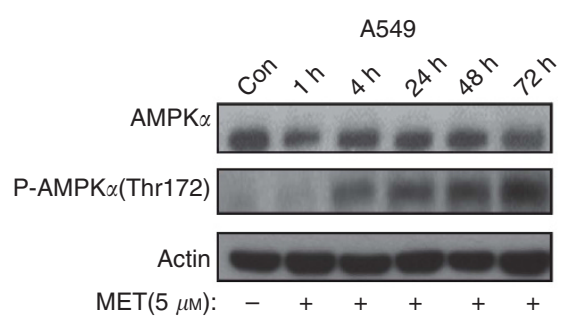

B

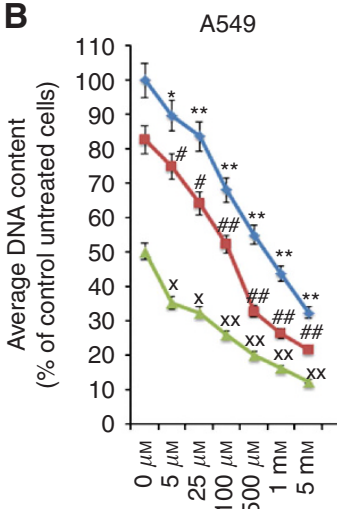

SK-MES

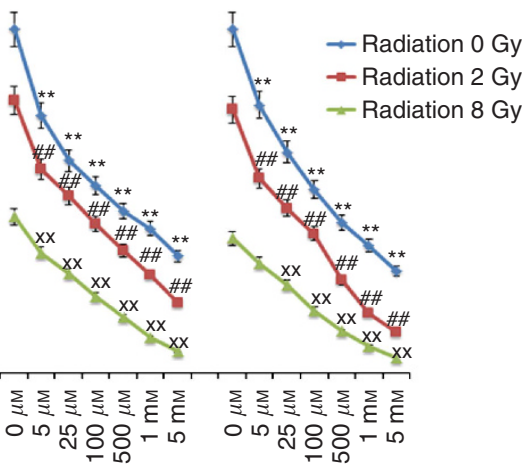

Metformin dose


Figure 1. Effects of MET and IR on proliferation, clonogenic survival and molecular signals in human LC cells. (A) Time course of MET effects on the pathways of AMPK. Cells were treated with $5 \mu \mathrm{M}$ MET doses for 1-72 h, lysed and probed with anti-total and -P-AMPK (T172) and -actin antibodies. Representative immunoblots from three experiments are shown. (B) A549, SK-MES1 and H1299 human LC cells were treated with increasing MET doses ( $5 \mu \mathrm{mol}-5 \mathrm{~mm}$ ) for $24 \mathrm{~h}$ before treatment with 0,2 or $8 \mathrm{~Gy}$ IR. Cells were fixed $48 \mathrm{~h}$ later. Proliferation results (mean \pm s.e.) of three independent experiments (including six replicates per condition in each experiment) are shown. Statistically significant differences compared with corresponding control cells (not treated with MET) within the 0,2 and $8 \mathrm{~Gy} I \mathrm{R}$ treatment groups are shown ( ${ }^{\star} P<0.05,{ }^{\star \star} P<0.001$ for $0 \mathrm{~Gy}$ group; ${ }^{\#} P<0.05$, ${ }^{\# \#} P<0.001$ for 2 Gy group; ${ }^{\times} P<0.05$ and ${ }^{x \times} P<0.001$ for 8 Gy group respectively). (C) Metformin and IR reduced clonogenic survival of LC cells. A549 and H1299 LC cells were first treated with increasing doses of MET (0-50 $\mu \mathrm{M})$ and subsequently with combination of 0,5 or $25 \mu \mathrm{M}$ MET and 0-8 Gy IR dose. Clonogenic survival was determined as outlined in Materials and Methods. Data were fitted into the linear quadratic model. Average results of three independent experiments are shown ( ${ }^{*}$ indicates statistical significance at $P<0.05$ ). (D) Comparison of MET and rapamycin effects in combination with IR on A549 human LC cell proliferation. Cells were treated with either $5 \mu \mathrm{M}, 100 \mu \mathrm{M}$ or $5 \mathrm{~mm}$ MET or 5,25 and $500 \mathrm{~nm}$ rapamycin for $24 \mathrm{~h}$, followed by treatment with either 0,2 or $8 \mathrm{~Gy}$ of IR and incubation for an additional $24 \mathrm{~h}$. Cells were fixed and proliferation rate was determined as outlined in (A). Results of 3-4 independent experiments (mean \pm s.e.) are shown. Statistically significant differences of MET or rapamycin treatments from no-drug treatment control in the same radiation dose group are shown: ${ }^{\star} P<0.05$; ${ }^{\star \star} P<0.001$ for 0 Gy group; ${ }^{\#} P<0.05$; ${ }^{\# \#} P<0.001$ for 2 Gy group; ${ }^{x} P<0.05$; ${ }^{x \times} P<0.001$ for 8 Gy treatment group.

Regulation of the cell cycle. Untreated A549 cells distributed mainly at the G1 phase (G1: $86.3 \%$, S phase: $10.5 \%$, G2-M: $3.5 \%$; Figure $3 \mathrm{~A})$. Metformin shifted cells into $\mathrm{S}$ phase $(5 \mu \mathrm{M}: \mathrm{G} 1: 76.5 \%$, S: $19.7 \%$, G2-M: $3.8 \%$ and $100 \mu \mathrm{M}$ : G1:77.4\%, S: $16.7 \%$ and G2-M:
$5.83 \%$, respectively). Ionising radiation ( $8 \mathrm{~Gy})$ induced the expected G2-M checkpoint arrest G2-M: $28.9 \%$ vs $3.5 \%$ in nonirradiated cells. Combined MET + IR treatment caused G1 shift, and reduced S and G2-M distribution, compared with IR-treated 

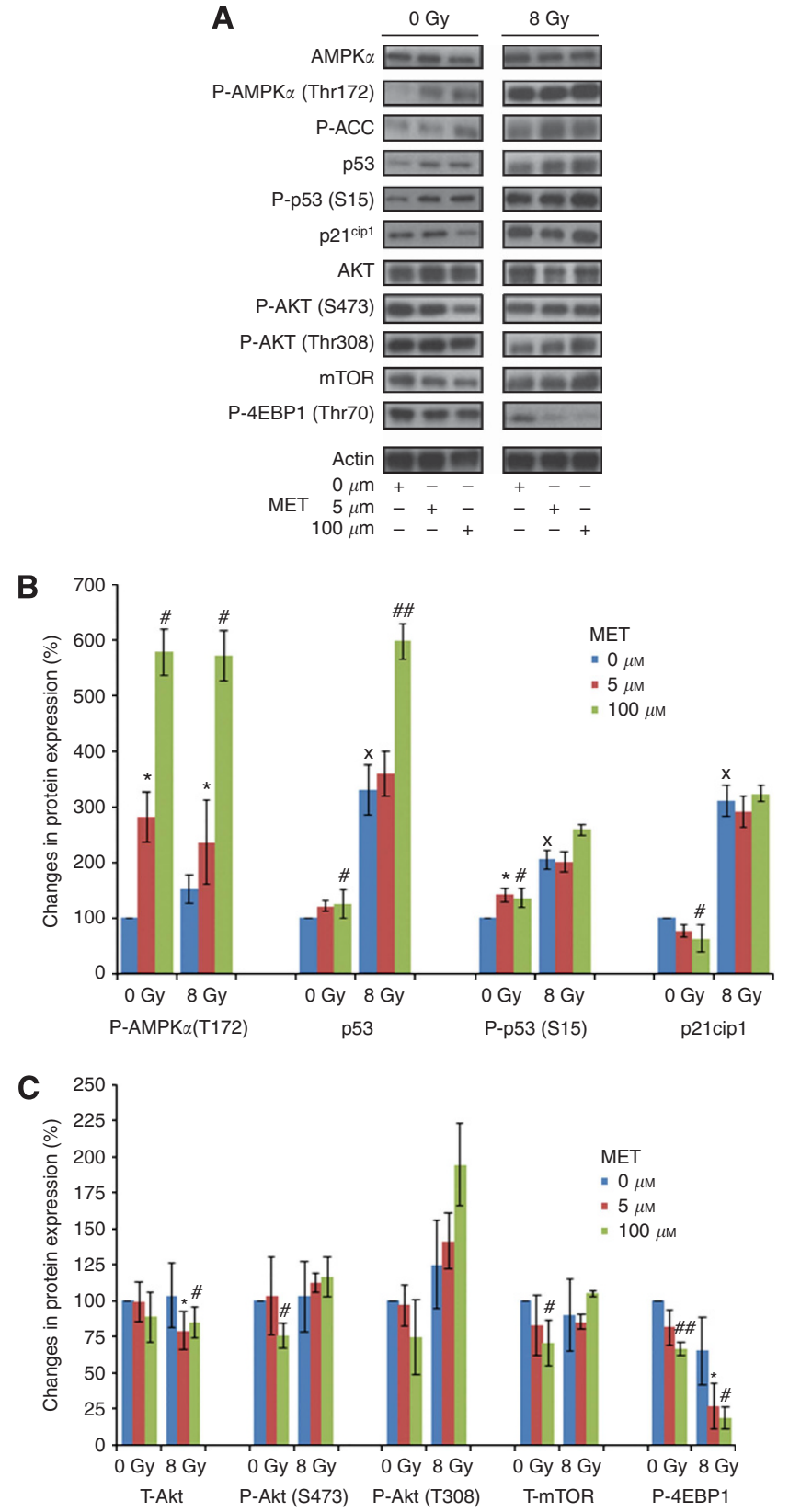

Figure 2. Metformin and IR mediate sustained modulation of molecular tumour growth and suppression pathways. A549 cells were treated with either MET (0, 5 or $100 \mu$ mol) for $48 \mathrm{~h}$, IR (0, 8 Gy) for $24 \mathrm{~h}$ or combined MET + IR treatments. Cells were washed and lysed. Lysates were analysed with immunoblotting using indicated antibodies. (A) Representative immunoblots are shown. (B and C) Mean \pm s.e. densitometric quantification values from three independent immunoblotting experiments are shown for markers of the AMPK-p53$\mathrm{p} 21^{\mathrm{cip} 1}$ and the Akt-mTOR-4EBP1 pathways, respectively. $\left({ }^{\mathrm{x}} P<0.05\right.$ between $0 \mu \mathrm{m}$ MET treatment groups (0 Gy vs $8 \mathrm{~Gy}$ ); ${ }^{\#} P<0.05$, ${ }^{\# \#} P<0.001$ between $5 \mu$ M MET group (0 Gy vs 8 Gy). ${ }^{\star} P<0.05$ compared to cells not treated with MET in the same IR group, respectively).

cells (G1: IR: $50.8 \%$ vs $5 \mu \mathrm{M}$ MET/8 Gy: $65.8 \%$ and $100 \mu \mathrm{M} \mathrm{MET/}$ 8 Gy: $66.9 \%$ and S: IR: $20.2 \%$ vs $5 \mu \mathrm{M} \mathrm{MET} / 8 \mathrm{~Gy}: 12.2 \%$ and $100 \mu \mathrm{M}$ MET/8 Gy: 14.7\%).

Induction of apoptosis. Forty-eight hours after MET treatment, A549 cells exhibited detectable levels of Annexin-V signal. However, IR (8 Gy) elevated Annexin-V signal, and this increased further in cells treated with combined $5 \mu \mathrm{M}$ or $25 \mu \mathrm{M}$ of MET and IR, respectively (Figure 3B).

Modulation of DDR signals by IR and MET. Similar to IR (Sanli et al, 2012b), MET treatment alone induced time-dependent increase in ATM levels and its activity detected as phosphorylated histone $\mathrm{H} 2 \mathrm{AX}(\gamma \mathrm{H} 2 \mathrm{AX})$ on immunoblotting (Figure 3C). To evaluate the subcellular distribution of this event, we examined $\gamma \mathrm{H} 2 \mathrm{AX}$ foci by immunofluorescence microscopy also. Ionising radiation $(4 \mathrm{~Gy})$ caused transiently $\gamma \mathrm{H} 2 \mathrm{AX}$ foci, an established marker of IR-induced DNA double-strand breaks (DSBs). Foci were reversed within $24 \mathrm{~h}$, indicating DNA repair (Figure 3D). In agreement with immunoblotting, MET alone also induced nuclear $\gamma \mathrm{H} 2 \mathrm{AX}$ foci, and combined MET and IR treatment led to sustained $\gamma \mathrm{H} 2 \mathrm{AX}$ foci at $24 \mathrm{~h}$, when IR effects were reversed.

Involvement of ATM and AMPK in the mechanism of action of $M E T$ and IR. To examine whether the ATM-AMPK pathway is involved in the mechanism of action of MET, we utilised first biochemical and molecular approaches to inhibit ATM. Figure 4A shows that MET $(5 \mu \mathrm{M})$ induces, within $48 \mathrm{~h}$, ATM activity (increased $\gamma \mathrm{H} 2 \mathrm{Ax}$ ), AMPK phosphorylation and expression of p $21^{\text {cip } 1}$. However, knocking down of ATM with specific siRNA eliminated cellular ATM levels and inhibited MET-induced activation of ATM, seen as blockade of $\gamma \mathrm{H} 2 \mathrm{AX}$ phosphorylation and AMPK $\alpha$ phosphorylation. We inhibited ATM with siRNA and the specific ATM inhibitor KU60019 (Golding et al, 2009) in irradiated cells also. Metformin induced ATM phosphorylation and activity (detected as $\gamma \mathrm{H} 2 \mathrm{AX}$ phosphorylation) in control cells, and enhanced further IR-induced ATM phosphorylation and activation in A549 cells (Figure 4B and C). Ataxia telengiectasiamutated knockdown eliminated total and phosphorylated ATM levels and blocked AMPK phosphorylation by both MET and IR (Figure 4B). Similarly, ATM inhibition with KU60019 blocked ATM activation (lack of $\gamma \mathrm{H} 2 \mathrm{Ax}$ ) by MET and IR, and inhibited AMPK $\alpha$ phosphorylation by MET in irradiated cells (Figure 4C).

To examine the role of AMPK in the mechanism of action of MET and IR, first A549 cells were pretreated with either vehicle alone or anti-AMPK $\alpha 1$ and $-\alpha 2$-specific siRNAs, and subjected to immunoblotting or proliferation assays. AMPK $\alpha 1 / 2-s i R N A s$ diminished significantly the expression of the enzyme and its activation by MET and IR, indicated by absence of phosphorylated AMPK $\alpha$, inhibition of ACC phosphorylation and blockage of p $21^{\text {cip } 1}$ induction (Figure 4D). Furthermore, knockdown of AMPK induced a dramatic stimulation of the activity of the Akt-mTOR pathway, similar to our earlier observations in AMPK $\alpha 1 / 2^{-/-}$MEFs (Sanli et al, 2012b). Lack of AMPK $\alpha 1 / 2$ induced AktT-308 phosphorylation, enhanced mTOR expression and phosphorylation as well as 4EBP1 phosphorylation. Importantly, AMPK inhibition eliminated the antiproliferative effects of both MET, IR and their combined effects (Figure 4E). To ensure the specificity of the effects of AMPK $\alpha 1 / 2$-siRNA, we subjected also WT- and AMPK $\alpha 1 / 2^{-/-}$-MEFs to MET (5-100 $\left.\mu \mathrm{M}\right)$. AMPK $\alpha 1 / 2^{-/-}$MEFs lacked AMPK $\alpha$ expression and phosphorylation, as well as the robust induction of $\mathrm{p} 21^{\mathrm{cip} 1}$ expression in response to MET seen in WT-MEFs. AMPK $\alpha 1 / 2^{-1-}$-MEFs had higher basal levels of phosphorylated 4EBP1, which did not respond to MET with reduction of this marker (Figure $4 \mathrm{~F}$ ). Further, AMPK $\alpha 1 / 2^{-{ }^{-}-}$MEFs showed severe resistance to the antiproliferative effects of both MET and IR (Figure 4G).

Metformin and IR effects on tumour growth. Balb/c-nude mice grafted with A549 or H1299 cells were subjected to treatments: MET, IR, both or neither. Animals tolerated tumour grafting and MET treatment with no noticeable changes in behaviour, eating habits or weight. Within 15 days after treatment initiation, A549 tumours of combined MET and IR treatment and H1299 tumours of the MET, IR or combined treatment began to show significant 

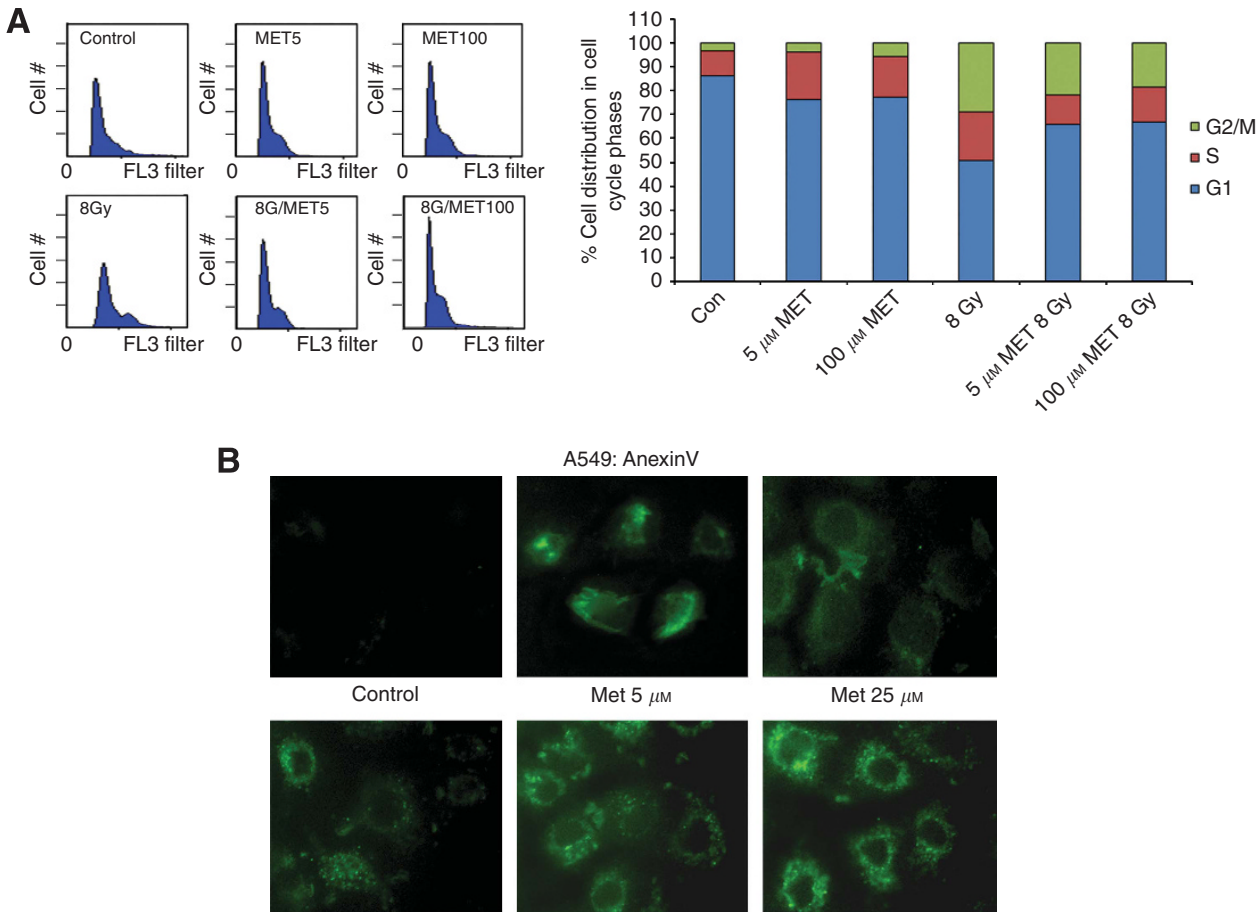

Met $5 \mu \mathrm{m}$

Met $25 \mu \mathrm{m}$
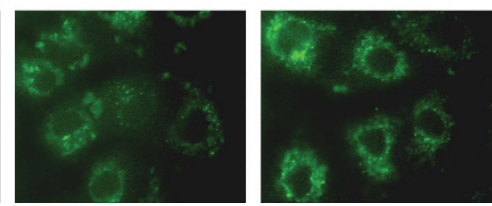

MET $5 \mu \mathrm{M}-8$ Gy

MET $25 \mu \mathrm{M}-8$ Gy

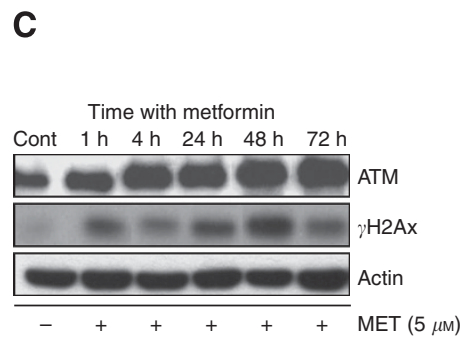

D

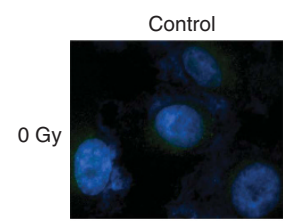

A549: $\gamma \mathrm{H} 2 \mathrm{Ax}$ $5 \mu \mathrm{M}$ MET

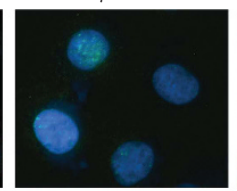
$25 \mu \mathrm{M} \mathrm{MET}$
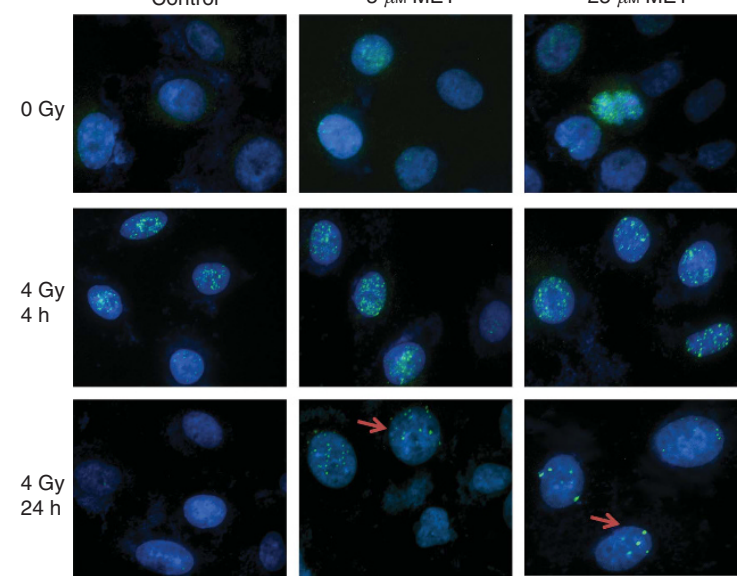

Figure 3. Modulation of cell cycle, apoptosis and DDR by MET and IR. (A) Cell cycle regulation by MET and IR. A549 cells were treated with 0, 5 or $100 \mu \mathrm{m}$ MET for $24 \mathrm{~h}$ before being subjected to either 0 or $8 \mathrm{~Gy}$ IR for additional $48 \mathrm{~h}$. Cells were fixed with ethanol and analysed by flow cytometry, as described in Materials and Methods. Representative images are shown. Graph shows results from three independent experiments. (B) Induction of apoptosis by MET and IR. Cells were treated with the indicated concentrations of MET for $48 \mathrm{~h}$ and exposure to 0 or $8 \mathrm{~Gy}$ IR. Twenty-four hours later, cells were fixed and labelled with an anti-Annexin- $V$ antibody, and visualised under a fluorescent microscope. Representative images from two independent experiments are shown. (C) Response of the DDR pathway to MET treatment. A549 cells were treated with $5 \mu \mathrm{M}$ MET for a period of 1-72 h, after which cells were lysed and lysates were probed with indicated antibodies. Representative immunoblots of four independent experiments are shown. (D) Induction of $\gamma \mathrm{H} 2 \mathrm{AX}$ foci by MET and IR. Cells were treated with the indicated concentrations of MET $24 \mathrm{~h}$ before $4 \mathrm{~Gy}$ IR. Following the indicated times after IR, cells were fixed and stained with DAPI (blue) and an antibody against $\gamma \mathrm{H} 2 \mathrm{Ax}$ ( $g r e e n)$ and visualised at $\times 40$. Representative images of multiple fields are shown for each treatment group.

inhibition of growth rate compared with untreated tumours $(P<0.01$; Figure 5A). At 60 days, xenografts treated with MET or IR alone were on average $31.0 \pm 5.8$ and $49.0 \pm 8.2 \%$ smaller than controls for A549, and $42.4 \pm 4.02$ and $61.9 \pm 5.62 \%$ for H1299 tumours. Combined treatment (MET + IR) showed over $62 \pm 8.4 \%$ growth reduction for A549 and $73.2 \pm 6.19 \%$ for $\mathrm{H} 1299$ tumours. As shown (Figure 5A), animals grafted with H1299 reached end point size earlier than the treated animals, and were euthanised at 50 days. Overall, in both animal models, MET and IR $(10 \mathrm{~Gy})$ treatments inhibited significantly tumour growth kinetics, the combined MET + IR treatment inhibited tumour growth further, but the combined effects were not additive.

Chronic regulation of expression and activity of ATM-AMPK/ Akt-mTOR pathways. Excised tumours, 8 weeks after a single dose of IR $(10 \mathrm{~Gy})$, continued MET or combined treatment, showed sustained enhancement of total ATM protein levels and its activity in irradiated tumours, evident by increased $\gamma \mathrm{H} 2 \mathrm{AX}$ (Figure 5B-D). However, ATM levels and activity ( $\gamma \mathrm{H} 2 \mathrm{AX}$ levels) were also increased by MET treatment alone, which induced 
A

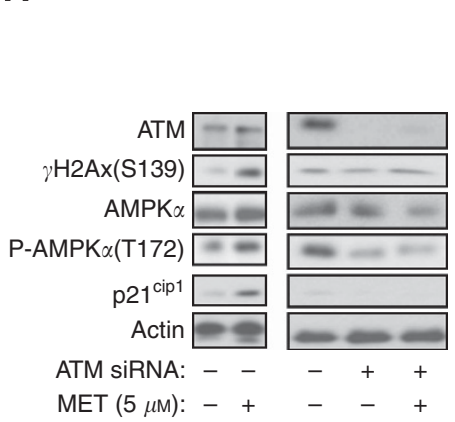

B

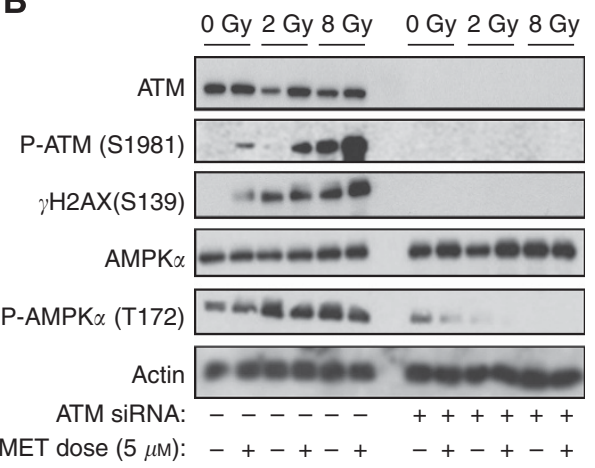

C

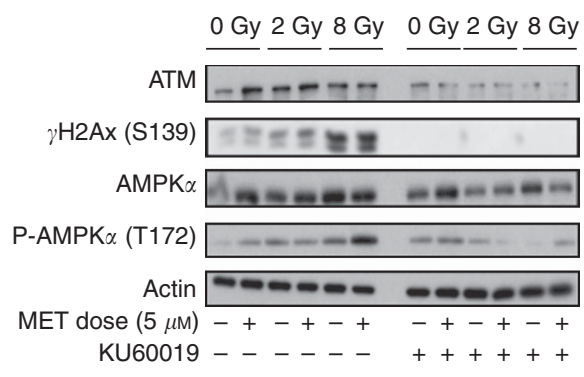

D

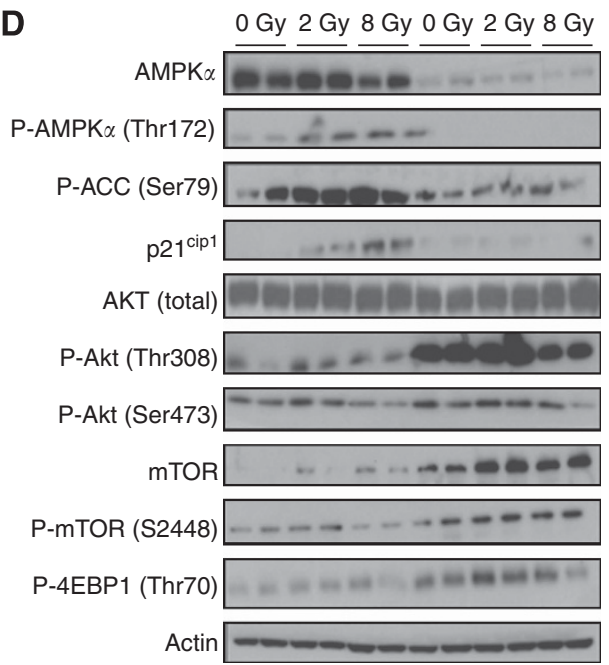

AMPK $\alpha 1 / 2$ siRNA -----++++++

MET dose $(5 \mu \mathrm{M})-+-+-+-++-+$

$\mathbf{F}$

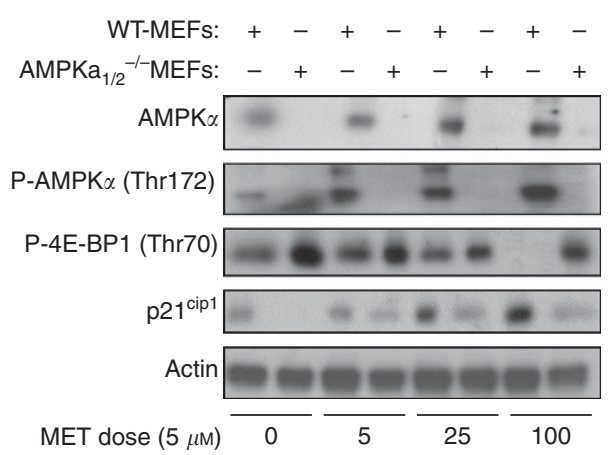

E

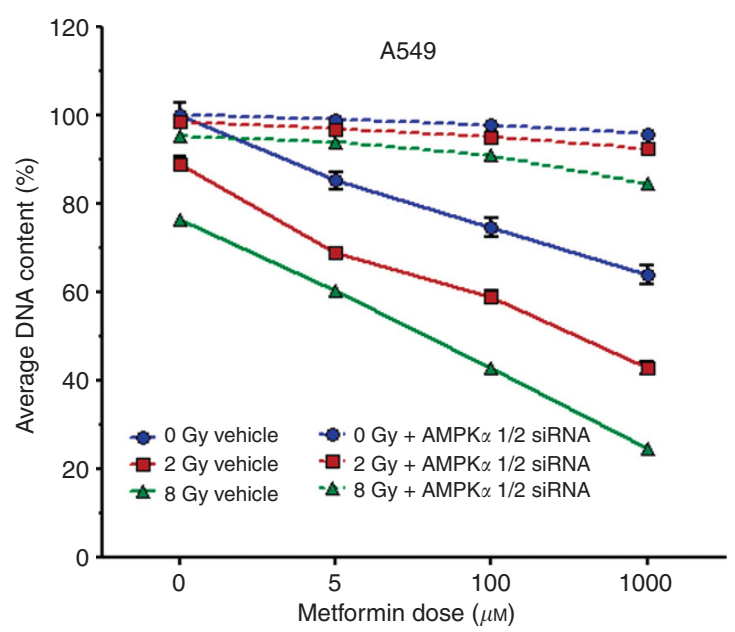

MEFs



Figure 4. Role of ATM and AMPK in the signalling and antiproliferative effects of MET and IR. (A-C) Ataxia telengiectasia-mutated regulates AMPK in response to MET and IR. A549 cells were either transfected with ATM-specific siRNA or control vector and incubated for $72 \mathrm{~h}$ (B) or incubated with the ATM-specific inhibitor KU60019 or vehicle for a period of $24 \mathrm{~h}$ (C), before treatment with $5 \mu \mathrm{M} \mathrm{MET} \mathrm{for} 48 \mathrm{~h}$ (A-C) and/or IR of 0 , 2 or 8 Gy $24 \mathrm{~h}$ (C) after initiation of MET treatment. After treatments, cells were washed, lysed and probed with indicated antibodies.

Representative immunoblots of three independent experiments are shown. AMP-activated kinase mediates the signalling and antiproliferative effects of MET and IR. A549 cells were pretreated with siRNAs against (D) AMPK $\alpha 1$ and AMPK $\alpha 2$ catalytic subunits or control vector for a period of $72 \mathrm{~h}$ before treatment with $5 \mu \mathrm{M}$ MET for a 48-h period and/or IR dose of 0, 2 or 8 Gy for a 24-h period. After treatment, cells were washed, lysed and probed with indicated antibodies. Representative immunoblots of three independent experiments are shown. (E) A549 cells were pretreated with control vector (vehicle) or siRNA sequences against AMPK $\alpha 1$ and AMPK $\alpha 2$ catalytic subunits for a period of $72 \mathrm{~h}$ before a 48 - $\mathrm{h}$ treatment with MET $(0 \mu \mathrm{M}-1 \mathrm{~mm})$ and a 24-h treatment with 0,2 or $8 \mathrm{~Gy}$ dose of IR. Proliferation results (mean \pm s.e.) of three independent experiments (six replicates per condition in each experiment) are shown. (F) WT and AMPK $\alpha 1 / 2^{-1-}$-MEFs were treated with MET $(0 \mu \mathrm{M}-100 \mu \mathrm{M})$ for a period of $48 \mathrm{~h}$. After treatment, cells were washed, lysed and probed with indicated antibodies. Representative immunoblots of three independent experiments are shown. (G) WT and AMPK $\alpha 1 / 2^{-1-}-\mathrm{MEFs}$ were treated with MET $(0 \mu \mathrm{M}-5 \mathrm{~mm})$ for a period of $48 \mathrm{~h}$ and/or the indicated doses of IR for $24 \mathrm{~h}$. Proliferation results (mean \pm s.e.) of three independent experiments are shown. 
A

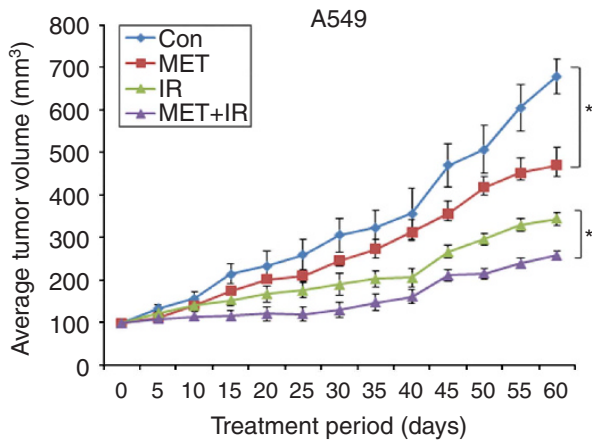

$\mathrm{H} 1299$

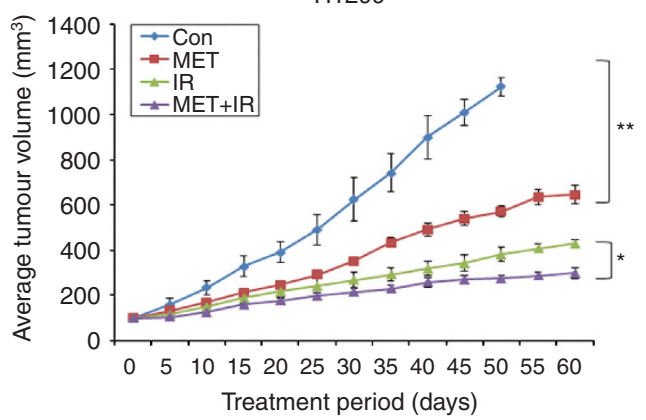

B

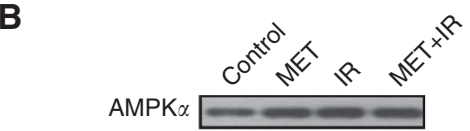

P-Thr172-AMPK $\alpha \square-\square$

$\mathrm{P}-\mathrm{ACC}$

ATM $=$

$\gamma \mathrm{H} 2 \mathrm{Ax}$

p53

P-p53 (S15)

- $21-\cdots$

AKT

P-AKT (Thr308)

P-AKT(S473)

mTOR

P-4EBP1

Actin
C

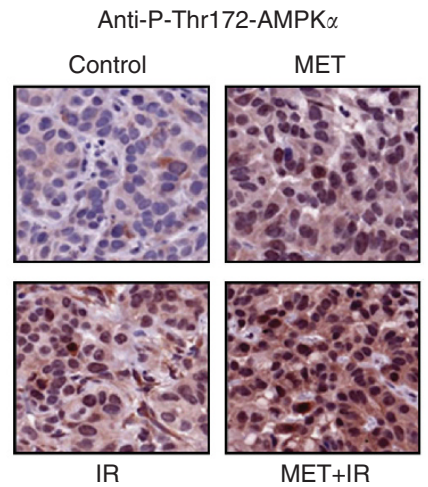

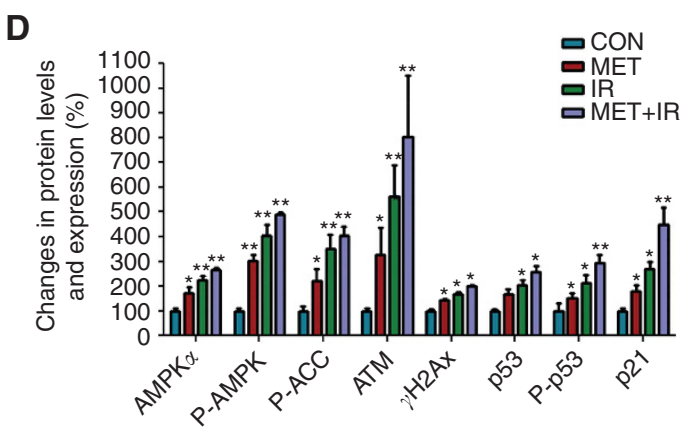

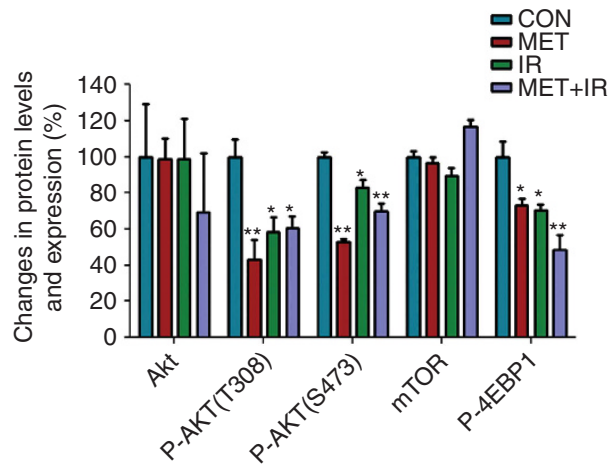

Figure 5. Inhibition of growth and molecular effects of MET and IR in human LC xenografts. (A) Effects on xenograft growth. Twenty-four and sixteen male Balb/c-nude mice were grafted into the right flank with $1 \times 10^{6}$ A549 or H1299 cells respectively. Treatment with MET, IR or combination was initiated once tumour volume reached $100 \mathrm{~mm}^{3}$. Tumour volume was measured every 5 days for a period of 8 weeks, as described in Materials and Methods. Average tumour volume data of four or six animals per treatment group are shown (mean \pm s.e.). Final tumour volumes were: A549: control: $679.5 \pm 50.6 \mathrm{~mm}^{3}$, MET: $470.53 \pm 35.2 \mathrm{~mm}^{3}$, IR: $342.9 \pm 21.8 \mathrm{~mm}^{3}$ and MET + IR: $257.9 \pm 15.2 \mathrm{~mm}^{3}$ and H1299: control: $1129.39 \pm 39.17 \mathrm{~mm}^{3}$, MET: $646.02 \pm 40.43 \mathrm{~mm}^{3}$, IR: $428.02 \pm 18.89 \mathrm{~mm}^{3}$ and MET + IR: $300.25 \pm 24.25 \mathrm{~mm}^{3}$. Statistically significant differences between the indicated treatment groups ( ${ }^{*} \mathrm{P}<0.05$ and $\left.* * \mathrm{P}<0.001\right)$. (B) Effects of MET and IR treatments on expression and activation of molecular markers. Tumours collected from control (CON), MET, IR and MET + IR treatment groups of A549 cohort were subjected to lysis and immunoblotting with antibodies against the indicated markers. Representative immunoblots of three independent experiments are shown. (C) Immunohistochemical analysis of P-AMPK expression. Analysis of A549 tumours from four different treatment groups using an anti-P-AMPKa (Thr172) antibody. Representative images from three independent experiments are shown. (D) Densitometric analysis of immunoblotting experiments ( $n=6$ in each group). Data are presented as mean \pm s.e. of normalised densitometry values. ${ }^{\star} P \leqslant 0.05 ;{ }^{\star \star} P \leqslant 0.001$ statistically significant difference between treatment groups and control for each marker.

further enhancement of the IR-induced levels of ATM expression and activity in tumours treated with MET and IR.

Ionising radiation and MET treatment also caused sustained enhancement of total AMPK $\alpha, \mathrm{P}-\mathrm{AMPK} \alpha^{\mathrm{Thr} 172}$ and phospho-(P)ACC levels, indicating stimulation of AMPK expression and activity (Figure 5B and D). Combined IR + MET treatment enhanced those markers further. AMPK $\alpha$ was increased by over two-fold by MET + IR compared to control; P-AMPK $\alpha^{\text {Thr172 }}$ was increased three-fold and four-fold by MET and IR $v$ s five-fold by MET + IR (Figure 5B and D) whereas P-ACC followed similar 
A

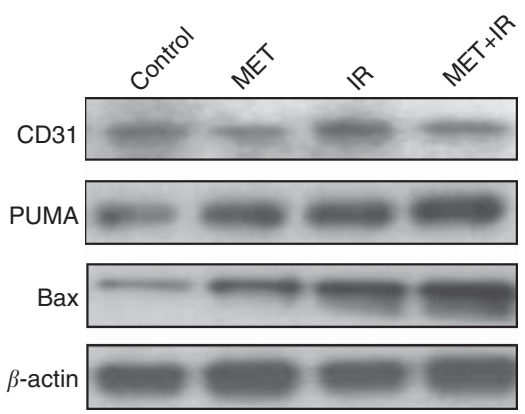

B
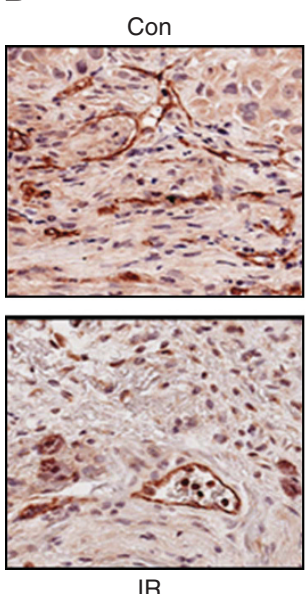

Anti-CD31 IHC
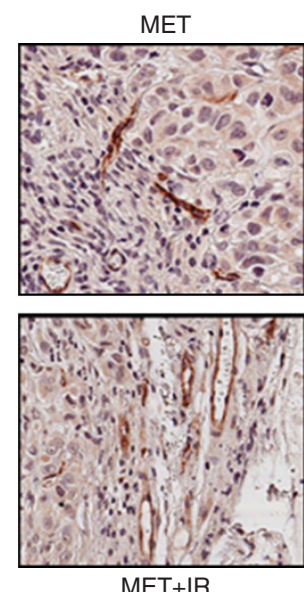

C

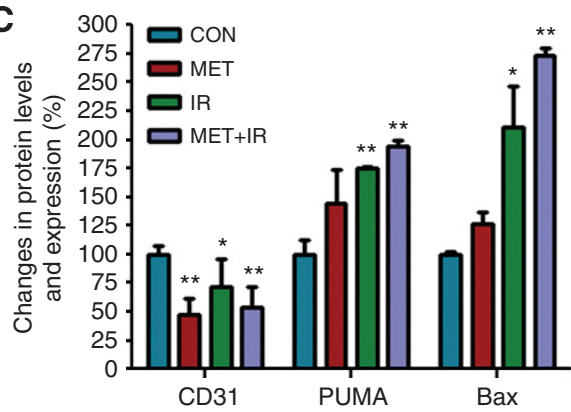

D
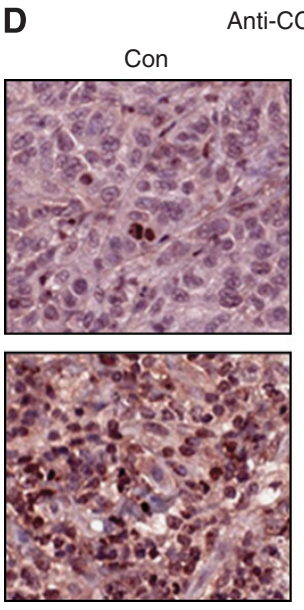

IR
MET
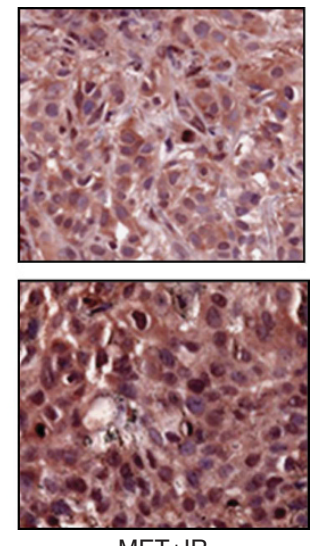

MET+IR

Figure 6. Metformin and IR reduce microvessels and enhance apoptosis markers in A549 LC tumours. (A) Effects on apoptosis markers. Lysates from control, MET-, IR- and MET + IR-treated tumours were analysed with immunoblotting using anti-CD31, -Puma, -Bax and -actin antibodies. Representative immunoblots are shown. (B) Representative images of anti-CD31 IHC analysis of A549 control (CON), MET-, IR- and MET + IRtreated tumours. (C) Densitometric analysis of immunoblotting results from lysates of tumours in all experimental groups ( $n=6$ in each group). Data are mean \pm s.e. of normalised densitometry values $\left({ }^{*}, P \leqslant 0.05 ;{ }^{*}, P \leqslant 0.001\right.$ statistically significant difference between treatment groups and control for each marker). (D) Effects MET and IR on expression of CC3. Representative images of IHC analysis of control (CON), MET-, IR- and $\mathrm{MET}+$ IR-treated tumours with an anti-CC3 antibody.

trends (Figure 5B and D). To confirm the immunoblotting results and examine the tumour gross cellular and subcellular distribution of AMPK activation, P-AMPK $\alpha^{\text {Thr172 }}$ levels were examined with IHC (Figure 5C). Activated P-AMPK $\alpha^{\text {Thr172 }}$ distributed in the cytoplasm and nucleus of tumour cells with MET- and IR-treated tumours, showing increased levels of AMPK $\alpha^{\text {Thr172 }}$ phosphorylation and further increase by the combined treatment.

Similar regulation to ATM and AMPK was shown for p53 and $\mathrm{p} 21^{\mathrm{cip} 1}$, respectively. Metformin and IR enhanced total p53, $\mathrm{P}-\mathrm{p} 53^{\mathrm{S} 15}$ and $\mathrm{p} 21^{\mathrm{cip} 1}$ levels but the combined MET + IR treatments produced significant further enhancement of those markers that approached additive effects on $\mathrm{p} 21^{\mathrm{cip} 1}$ expression (Figure 5B and D).

We detected no significant differences in the total AKT levels between individual MET or IR treatments and untreated tumours (Figure 5B and D). Combined MET and IR treatment induced a trend for reduced total AKT expression. Ionising radiation- and METtreated tumours showed reduced Akt-T308 and S473 phosphorylation, and so did the ones treated with combined MET + IR, although this was lower than MET alone (Figure 5B and D). We observed no consistent modulation of total mTOR levels by either treatment; however, IR and MET led to a significant additive inhibition of mTOR activity indicated by reduced 4EBP1 phosphorylation (MET: $26.8 \pm 4.8 \%$; IR: $29.5 \pm 5.2 \%$ vs MET + IR: $51.5 \pm 8.3 \%$ reduction, Figure $5 \mathrm{~B}$ and $\mathrm{D})$, consistent with in vitro results (Figure 2).

Modulation of tumour vasculature by MET and IR. Irradiated tumours showed reduced endothelial angiogenesis marker CD31 expression using immunoblotting (by $29.3 \pm 3.9 \%$, Figure 6A). However, tumours of animals treated with MET or MET + IR showed higher reductions of CD31 levels (by $51 \pm 4.1 \%$ and $47 \pm 4.9 \%$, respectively, Figure $6 \mathrm{C}$ ). In agreement with these results, IHC experiments showed reduced microvessel density in tumours treated with MET, IR or the combined treatment (Figure 6B).

Regulation of pro-apoptotic markers. Individual MET and IR treatments increased the apoptotic markers BAX and PUMA in tumours. This was statistically significant only for irradiated tumours (Figure 6A and B). Metformin increased further the IR induction of the two markers. To verify further the activation of the apoptotic pathway, we examined the levels of CC3 with IHC. Metformin increased CC3 levels in non-irradiated tumours but more significantly so in irradiated tumours (Figure 6D).

\section{DISCUSSION}

The potential of MET to offer true systemic antiproliferative effects in humans has been debated since, to date, studies used clinically intolerable $(\mathrm{mm})$ concentrations of the drug to achieve significant inhibition of cancer cell growth. Ben Sahra et al (2008) and Buzzai et al (2007) showed inhibition of prostate, breast and colon cancer cell survival with 1-5 mM MET. In early studies, we also observed resistance of breast (MCF7 and MDAMB231) and prostate cancer (PC3) cells to low $\mu \mathrm{M}$ dose MET, compared with NSCLC A549, 
H1299 and SK-MES1 cells (Supplementary Figure S1). Those results formed the basis of the present study, which shows significant antiproliferative effects of $5-100 \mu \mathrm{M}$ MET in NSCLC models (Figure 1). Most human studies report plasma Cmax of 1$2 \mu \mathrm{g} \mathrm{ml}^{-1}(\sim 10 \mu \mathrm{M})$. Steady state concentrations of $7.8 \mu \mathrm{M}$ were described with daily oral MET of $850-1700 \mathrm{mg}$, whereas maximum concentrations up to $38 \mu \mathrm{M}$ or higher were shown in controlled studies (Lipska et al, 2011). Diabetic patients are treated with up to 2.5-3.0 g MET daily without significant toxicity. Lactic acidosis is the most significant, but rare, complication of MET therapy but no threshold plasma concentration of MET for lactic acidosis has been defined (Lipska et al, 2011). To date, there are no reports of increased normal human tissue toxicity with radiotherapy in patients treated with MET. Consistently, we observed no inhibition of proliferation of normal human embryonic lung fibroblasts (MRC5) with low MET doses (1-25 $\mu$; Supplementary Figure S2), indicating that MET has the potential to increase the therapeutic ratio of radiotherapy in LC.

Effects of MET on NSCLC genotypes. To explore the antitumour effect of MET in different NSCLC genotypes, we used lines that represent common histologies and mutation profile of NSCLC (A549 adenocarcinoma: LKB1-deficient (nonsense mutation of codon 37 leading to stop codon), K-Ras G12S-activating mutant, p53-WT; H1299 adenocarcinoma: LKB1-WT, p53-deficient (TP53 partial deletion) and SK-MES squamous cell carcinoma: LKB1WT, p53-deficient (exon 8 mutation); Carretero et al, 2004). The efficacy of MET to inhibit proliferation or clonogenic survival in all these models of NSCLC indicates potential for clinical development in most NSCLC histologies.

Radiosensitisation by MET. For relevance to clinical radiotherapy, we treated cells and tumours with standard radiation doses of 2-10 Gy, using clinical linear accelerators. Both low and higher doses of MET augmented the antiproliferative effects of both 2 and $8 \mathrm{~Gy}$ IR, and statistical analysis of the interaction indicated synergy between the two treatments (see Results and Supplementary Table S1). Further, we observe global antitumour and radiosensitising action of MET (5-25 $\mu \mathrm{M})$ in clonogenic assays (Figure 1C). We show radiosensitising effects in LC at clinically achievable doses of MET (5-25 $\mu \mathrm{M})$. Recently, Song et al (2012) showed radiosensitisation of breast cancer and sarcoma cells by MET, but this was achieved at mM doses of MET. However, Skinner et al (2012) showed that $25 \mu \mathrm{M}$ MET could decrease the surviving fraction of head + neck cancer cells after 2 Gy IR (SF2). Overall, MET inhibited significantly NSCLC cell and tumour growth, and enhanced the IR-mediated cytotoxicity (Figures 1 and 5).

Comparison with other targeted therapeutics. As MET modulates mTOR activity, we compared it with the macrocyclic lactone mTOR inhibitor rapamycin (Sirolimus). In human pharmacokinetic studies, 2-3 mg oral rapamycin led to Cmax plasma levels of 5-29 nM, with limited grade 1-2 toxicity, but higher doses produced grade 3-4 dose-limiting toxicity including mucositis, thrombocytopenia, diarrhoea and hyperglycaemia (Jimeno et al, 2008). In irradiated cells, MET $(5-100 \mu \mathrm{M})$ caused similar antiproliferative effects as $5-500 \mathrm{~nm}$ rapamycin (Figure $1 \mathrm{D}$ ). One of the reasons specific mTOR inhibitors failed to show clinical benefit in some tumours is their property to induce feedback activation of the PI3k-Akt axis, promoting survival of tumours and resistance to cytotoxics (Vazquez-Martin et al, 2009). Similar to others (Zakikhani et al, 2010), we observed inhibition of 4EBP1 phosphorylation by rapamycin but enhancement of Akt-T308 and Akt-S473 phosphorylation at 24 and $48 \mathrm{~h}$ of treatment (Supplementary Figure S4). This suggests that MET offers benefits over mTOR inhibitors as it inhibits not only mTOR but also Akt phosphorylation in tumours (Figures 2,4,5). We have also compared MET with EGFR inhibitor gefitinib (1-4 $\mu \mathrm{M}$ used earlier; Tanaka et al, 2008). Gefitinib (1 $\mu \mathrm{M}$ or higher) inhibited proliferation of non-irradiated NSCLC cells more effectively than $5 \mu \mathrm{M}$ MET, showed comparable antiproliferative action with 5-100 $\mu \mathrm{M}$ MET in cells irradiated with 2 Gy but weaker radioenhancing action compared with 5-100 $\mu \mathrm{M}$ MET when combined with 8 Gy IR (Supplementary Figure S5).

\section{Mechanism of action of IR and MET}

Role of LKB1 and p53. Metformin is an inhibitor of complex I of the mitochondria respiratory chain and is proposed to function as an energy restriction mimetic, which leads to increased AMP levels and activation of AMPK through binding to $\gamma$-subunit (Steinberg and Kemp, 2009). It was suggested that MET requires LKB1 to activate AMPK, inhibit $\mathrm{MTOR}$ and suppresses proliferation and oncogenesis (Dowling et al, 2007; Shaw et al, 2005). Others argued that MET inhibits growth (Buzzai et al, 2007) or induces radiosensitisation (Skinner et al, 2012) selectively in tumours and cancer cells lacking functional p53. It is possible that specific p53null tumours may be more sensitive to MET. We did observe greater sensitivity to low-dose MET in non-irradiated and irradiated p53-null NSCLC cells H1299 and SK-MES compared with A549 (p53-WT; Figure1 and Supplementary Figure S5). However, MET caused significant dose-dependent inhibition of proliferation and radiosensitisation in both LKB1- and p53-WT or -deficient cells, and inhibited growth of LKB1-deficient p53-WT (A549) xenografts (Figures 1 and 5). Further, p53-null MDAMB231 breast cancer and PC3 prostate cancer cells demonstrated higher resistance to MET compared with NSCLC cells. (Supplementary Figure S1).

Role of ATM. Earlier, we suggested that activation of the AMPKp53-p2 $1^{\text {cip } 1}$ pathway in response to IR was ATM-dependent (Sanli et al, 2010 and Sanli et al, 2012b). Other studies showed that ATM regulates AMPK in response to cytotoxics such as etoposide (47), and recent reports suggest that MET mediates an ATM-mediated DDR-like response (Vazquez-Martin et al, 2011). Here, we showed that MET increased expression and activation of ATM in cells and tumours in association with activation of the AMPK-p53-p2 $1^{\text {cip1 }}$ axis. Metformin induced nuclear $\gamma \mathrm{H} 2 \mathrm{AX}$ foci, resembling those assembled at sites of DNA DSBs (Figure 3), indicating that the drug or its effectors are active within the nucleus. Presently, there is no evidence that MET induces genomic stress or DSBs. $\gamma \mathrm{H} 2 \mathrm{AX}$ foci sustained long after irradiation are likely the result of enhanced ATM activity related to potential replication stress (Menendez et al, 2011) or oxidative stress developing in cells, as MET suppresses mitochondria respiration. Such results are consistent with a developing notion that MET mediates a pseudo DDR that could protect against oncogenesis (Menendez et al, 2011). Future studies should investigate in depth the mechanism of regulation of ATM by MET. Here, we show that inhibition of ATM with either KU60019 or siRNA blocks MET- and IR-induced phosphorylation of AMPK $\alpha$ (Figure $4 \mathrm{~A}-\mathrm{C}$ ) indicated that ATM functions upstream of AMPK in the pathways of action of MET and IR.

Role of AMPK. To date, our work suggested that (i) AMPK is a key sensor of IR signals (Sanli et al, 2010), (ii) AMPK subunit expression is tightly regulated by IR (Sanli et al, 2012b) and (iii) lack of AMPK destabilises the Akt-mTOR and DDR pathways, leading to inhibition of radiation responsiveness (Sanli et al, 2012b). Consistently, here we observed enhanced expression and activation of AMPK in NSCLC cells and tumours in response to IR (Figures 2 and 5). Metformin induced a robust phosphorylation of AMPK in non-irradiated and irradiated cells and tumours, and increased total AMPK $\alpha$ levels in tumours (Figures 1,2,5). Metformin may indeed regulate $A M P K \alpha$ gene expression in 
addition to activation. Earlier, we suggested that sestrin 2, member of a family of p53-dependent stress-induced genes, facilitates $A M P K$ subunit gene expression and activation in response to IR (Sanli et al, 2012a) and others (Rocha et al, 2011) proposed that sestrins mediate the AMPK response to combined MET and chemotherapy treatments.

Individual and combined treatments with MET and IR produced a sustained enhancement of signalling events downstream of AMPK, such as increased total and phosphorylated p53 and $\mathrm{p} 21^{\mathrm{cip} 1}$ levels, as well as inhibition of mTOR activity, indicated by inhibition of 4EBP1 phosphorylation in cells and tumours (Figures 2 and 5). With AMPK $\alpha 1 / 2$ knockdown in NSCLC cells (siRNA) and knock-out models (AMPK $\alpha 1 / 2^{-1-}-\mathrm{MEFs}$ ), we demonstrate the dependency of those signalling events on AMPK and the key role of this enzyme in mediation of the antiproliferative effects of both MET and IR (Figure 4D-G). Knockdown of AMPK $\alpha 1 / 2$ produced in cancer cells the radio-resistant molecular expression phenotype we observed earlier in AMPK $\alpha 1 / 2^{-1-}$ MEFs (Sanli et al, 2012b) with induction of mTOR expression and activity (P-4EBP1) and phosphorylation of Akt-T308 and mTORS2448 (Rosner et al, 2010; Figure 4D), both of which are markers of increased activity of the PI3k-Akt survival pathway. These results verify and strengthen our earlier observations on the role of AMPK in radiation responses of cancer cells and support the notion that ATM and AMPK are points of convergence of molecular signals activated by both IR and MET.

Inhibition of 4EBP1 phosphorylation and induction of $\mathrm{p} 21^{\mathrm{cip} 1}$, which were observed in response to MET, are expected to inhibit protein synthesis and growth of cellular biomass, and to induce G1/S checkpoints. We observed an increase of cells at S phase with MET treatment (Figure 3). More effective modulation of p53/ $\mathrm{p} 21^{\mathrm{cip} 1}$ and mTOR by MET in irradiated cells is expected to inhibit cycling further and promote G1 arrest, which we did observe (Figure 3) and has been described by others (Ben Sahra et al, 2008; Rattan et al, 2011).

Metformin effects on angiogenesis. Reports on the effects of MET on tumour microvasculature remain controversial. AMP-activated kinase is suggested to participate in angiogenesis (Nagata et al, 2003) and MET was suggested to normalise tumour vasculature in breast cancer and inhibit angiogenesis in ovarian cancer xenografts (Rattan et al, 2011). Consistent with the latter, MET and IR reduced microvascular density and expression of the endothelial marker CD31 in NSCLC tumours (Figure 5A-C). These events may participate in the enhancement of IR-induced cytotoxicity seen with MET and contribute to sustained activation of the ATMAMPK axis.

Metformin effects on apoptosis. The significant induction of expression and phosphorylation of p53 we detected with MET in vitro and in vivo (Figures 2 and 5) suggested that apoptotic cell death is activated. Combined IR + MET induced the greatest enhancement in apoptosis markers in cultured NSCLC cells, detected by the Annexin- $\mathrm{V}$ assay (Figure 3B), and in tumours, detected as enhanced expression of the apoptotic markers Bax, Puma and CC3 (Figure 6). They suggest activation of the intrinsic (mitochondria-dependent) and the common apoptotic pathways, which lead to apoptotic death. AMP-activated kinase activation, MET and IR were described to stimulate autophagy (Chaachouay et al, 2011; Mihaylova and Shaw, 2011; Shi et al, 2012), which is suggested to facilitate survival under metabolic stress. However, it remains highly controversial whether autophagy is a reliable marker of cell survival or cell death in cells subjected to cytotoxic therapy (Galluzzi et al, 2007). Our results are consistent with those obtained when MET was combined with paclitaxel (Rocha et al, 2011).

\section{CONCLUSIONS}

In conclusion, this study demonstrates that MET doses that are achieved safely in human plasma inhibit proliferation and radiosensitise NSCLC. Metformin inhibits tumour growth and enhances tumour response and the pro-apoptotic and antiangiogenic effects of IR. In cells and tumours, MET mediates activation of tumour suppressor and inhibition of survival pathways. The ATM-AMPK pathway is a point of convergence of IR and MET signals and the mediator of the antitumour action of the two agents. The work presented here provides a preclinical basis to begin investigation of MET in combination with radiotherapy in early-phase clinical trials in NSCLC.

\section{ACKNOWLEDGEMENTS}

We thank Carrie Schultz and Dr Thomas Farrell, Radiation Therapy and Physics, Juravinski Cancer Center, for their work to facilitate the planning and delivery of radiotherapy to tissue cultures and tumours of grafted animals. We thank Dr Jacek M Kwiecien, McMaster University, for his kind assistance with animal autopsies and Dr Robert Bristow, Department of Radiation Oncology, University of Toronto for scientific advice. We greatly appreciate the donation of WT- and AMPK $\alpha 1 / 2^{-/-}$-MEFs by Dr Benoit Viollet (INSERM, France). This work was supported by grants by the Canadian Association of Radiation Oncologists RAZCER program to TT and the Canadian Institutes of Health Research to GS.

\section{REFERENCES}

Ben Sahra I, Laurent K, Loubat A, Giorgetti-Peraldi S, Colosetti P, Auberger P, Tanti JF, Le Marchand-Brustel Y, Bost F (2008) The antidiabetic drug metformin exerts an antitumoral effect in vitro and in vivo through a decrease of cyclin D1 level. Oncogene 27: 3576-3586.

Bowker SL, Majumdar SR, Veugelers P, Johnson JA (2006) Increased cancer-related mortality for patients with type 2 diabetes who use sulfonylureas or insulin: Response to Farooki and Schneider. Diabetes Care 29: 1990-1991.

Brachmann S, Fritsch C, Maira SM, Garcia-Echeverria C (2009) PI3K and mTOR inhibitors: a new generation of targeted anticancer agents. Curr Opin Cell Biol 21: 194-198.

Bussink J, van der Kogel AJ, Kaanders JH (2008) Activation of the PI3-K/AKT pathway and implications for radioresistance mechanisms in head and neck cancer. Lancet Oncol 9: 288-296.

Buzzai M, Jones RG, Amaravadi RK, Lum JJ, DeBerardinis RJ, Zhao F, Viollet B, Thompson CB (2007) Systemic treatment with the antidiabetic drug metformin selectively impairs p53-deficient tumor cell growth. Cancer Res 67: 6745-6752.

Carretero J, Medina PP, Pio R, Montuenga LM, Sanchez-Cespedes M (2004) Novel and natural knockout lung cancer cell lines for the LKB1/STK11 tumor suppressor gene. Oncogene 23: 4037-4040.

Chaachouay H, Ohneseit P, Toulany M, Kehlbach R, Multhoff G, Rodemann HP (2011) Autophagy contributes to resistance of tumor cells to ionizing radiation. Radiother Oncol 99: 287-292.

Chou TC (2010) Drug combination studies and their synergy quantification using the Chou-Talalay method. Cancer Res 70: 440-446.

Chou TC, Talalay P (1984) Quantitative analysis of dose-effect relationships: the combined effects of multiple drugs or enzyme inhibitors. Adv Enzyme Regul 22: 27-55.

Curran Jr WJ (2003) Evolving chemoradiation treatment strategies for locally advanced non-small-cell lung cancer. Oncology 17: 7-14.

Dowling RJ, Zakikhani M, Fantus IG, Pollak M, Sonenberg N (2007) Metformin inhibits mammalian target of rapamycin-dependent translation initiation in breast cancer cells. Cancer Res 67: 10804-10812.

Dowling RO, Niraula S, Stambolic V, Goodwin PJ (2012) Metformin in cancer: translational challenges. J Mol Endocrinol 48(3): R31-R43. 
Evans JM, Donnelly LA, Emslie-Smith AM, Alessi DR, Morris AD (2005) Metformin and reduced risk of cancer in diabetic patients. BMJ 330: 1304-1305.

Galluzzi L, Maiuri MC, Vitale I, Zischka H, Castedo M, Zitvogel L, Kroemer G (2007) Cell death modalities: classification and pathophysiological implications. Cell Death Differ 14: 1237-1243.

Golding SE, Rosenberg E, Valerie N, Hussaini I, Frigerio M, Cockcroft XF, Chong WY, Hummersone M, Rigoreau L, Menear KA, O'Connor MJ, Povirk LF, van Meter T, Valerie K (2009) Improved ATM kinase inhibitor KU-60019 radiosensitizes glioma cells, compromises insulin, AKT and ERK prosurvival signaling, and inhibits migration and invasion. Mol Cancer Ther 8: 2894-2902.

Goodwin PJ, Ligibel JA, Stambolic V (2009) Metformin in breast cancer: time for action. J Clin Oncol 27: 3271-3273.

Goodwin PJ, Stambolic V, Lemieux J, Chen BE, Parulekar WR, Gelmon KA, Hershman DL, Hobday TJ, Ligibel JA, Mayer IA, Pritchard KI, Whelan TJ, Rastogi P, Shepherd LE (2011) Evaluation of metformin in early breast cancer: a modification of the traditional paradigm for clinical testing of anti-cancer agents. Breast Cancer Res Treat 126: 215-220.

Gwinn DM, Shackelford DB, Egan DF, Mihaylova MM, Mery A, Vasquez DS, Turk BE, Shaw RJ (2008) AMPK phosphorylation of raptor mediates a metabolic checkpoint. Mol Cell 30: 214-226.

Huang X, Wullschleger S, Shpiro N, McGuire VA, Sakamoto K, Woods YL, McBurnie W, Fleming S, Alessi DR (2008) Important role of the LKB1AMPK pathway in suppressing tumorigenesis in PTEN-deficient mice. Biochem J 412: 211-221.

Iliopoulos D, Hirsch HA, Struhl K (2011) Metformin decreases the dose of chemotherapy for prolonging tumor remission in mouse xenografts involving multiple cancer cell types. Cancer Res 71: 3196-3201.

Jimeno A, Rudek MA, Kulesza P, Ma WW, Wheelhouse J, Howard A, Khan Y, Zhao M, Jacene H, Messersmith WA, Laheru D, Donehower RC, GarrettMayer E, Baker SD, Hidalgo M (2008) Pharmacodynamic-guided modified continuous reassessment method-based, dose-finding study of rapamycin in adult patients with solid tumors. J Clin Oncol 26: 4172-4179.

Jiralerspong S, Palla SL, Giordano SH, Meric-Bernstam F, Liedtke C, Barnett CM, Hsu L, Hung MC, Hortobagyi GN, Gonzalez-Angulo AM (2009) Metformin and pathologic complete responses to neoadjuvant chemotherapy in diabetic patients with breast cancer. J Clin Oncol 27: 3297-3302.

Laplante M, Sabatini DM (2009) mTOR signaling at a glance. J Cell Sci 122: 3589-3594.

Lipska KJ, Bailey CJ, Inzucchi SE (2011) Use of metformin in the setting of mild-to-moderate renal insufficiency. Diabetes Care 34: 1431-1437.

Lord JM, Flight IH, Norman RJ (2003) Metformin in polycystic ovary syndrome: systematic review and meta-analysis. BMJ 327: 951-953.

Mak IWY, Turcotte RE, Popovic S, Singh G, Ghert M (2011) AP-1 as a Regulator of MMP-13 in the Stromal Cell of Giant Cell Tumor of Bone. Biochem Res Int 2011: 164197.

Menendez JA, Cufi S, Oliveras-Ferraros C, Martin-Castillo B, Joven J, Vellon L, Vazquez-Martin A (2011) Metformin and the ATM DNA damage response (DDR): accelerating the onset of stress-induced senescence to boost protection against cancer. Aging 3: 1063-1077.

Mihaylova MM, Shaw RJ (2011) The AMPK signalling pathway coordinates cell growth, autophagy and metabolism. Nat Cell Biol 13: 1016-1023.

Nagata D, Mogi M, Walsh K (2003) AMP-activated protein kinase (AMPK) signaling in endothelial cells is essential for angiogenesis in response to hypoxic stress. J Biol Chem 278: 31000-31006.

Petroulakis E, Mamane Y, Le Bacquer O, Shahbazian D, Sonenberg N (2006) mTOR signaling: implications for cancer and anticancer therapy. $\mathrm{Br} \mathrm{J}$ Cancer 94: 195-199.

Rattan R, Graham RP, Maguire JL, Giri S, Shridhar V (2011) Metformin suppresses ovarian cancer growth and metastasis with enhancement of cisplatin cytotoxicity in vivo. Neoplasia 13: 483-491.

Rocha GZ, Dias MM, Ropelle ER, Osorio-Costa F, Rossato FA, Vercesi AE, Saad MJ, Carvalheira JB (2011) Metformin amplifies chemotherapy-induced AMPK activation and antitumoral growth. Clin Cancer Res 17: 3993-4005.

Rosner M, Siegel N, Valli A, Fuchs C, Hengstschlager M (2010) mTOR phosphorylated at S2448 binds to raptor and rictor. Amino Acids 38: 223-228.

Sanli T, Linher-Melville K, Tsakiridis T, Singh G (2012a) Sestrin2 modulates AMPK subunit expression and its response to ionizing radiation in breast cancer cells. PLoS One 7: e32035.

Sanli T, Liu C, Rashid A, Hopmans S, Tsiani E, Schultz C, Farrell T, Singh G, Wright J, Tsakiridis T (2011) Lovastatin sensitizes lung cancer cells to ionizing radiation. Modulation of growth and tumour suppressor signalling pathways and induction of apoptosis. J Thorac Oncol 6(3): 439-450.

Sanli T, Rashid A, Liu C, Harding S, Bristow RG, Cutz JC, Singh G, Wright J, Tsakiridis T (2010) Ionizing radiation activates AMP-activated kinase (AMPK): a target for radiosensitization of human cancer cells. Int J Radiat Oncol Biol Phys 78: 221-229.

Sanli T, Storozhuk Y, Linher-Melville K, Bristow RG, Laderout K, Viollet B, Wright J, Singh G, Tsakiridis T (2012b) Ionizing radiation regulates the expression of AMP-activated protein kinase (AMPK) in epithelial cancer cells: modulation of cellular signals regulating cell cycle and survival. Radiother Oncol 102: 459-465.

Shaw RJ, Lamia KA, Vasquez D, Koo SH, Bardeesy N, Depinho RA, Montminy M, Cantley LC (2005) The kinase LKB1 mediates glucose homeostasis in liver and therapeutic effects of metformin. Science 310: $1642-1646$.

Shi WY, Xiao D, Wang L, Dong LH, Yan ZX, Shen ZX, Chen SJ, Chen Y, Zhao WL (2012) Therapeutic metformin/AMPK activation blocked lymphoma cell growth via inhibition of mTOR pathway and induction of autophagy. Cell Death Dis 3: e275.

Skinner HD, Sandulache VC, Ow TJ, Meyn RE, Yordy JS, Beadle BM, Fitzgerald AL, Giri U, Ang KK, Myers JN (2012) TP53 disruptive mutations lead to head and neck cancer treatment failure through inhibition of radiation-induced senescence. Clin Cancer Res 18: 290-300.

Song CW, Lee H, Dings RP, Williams B, Powers J, Santos TD, Choi BH, Park HJ (2012) Metformin kills and radiosensitizes cancer cells and preferentially kills cancer stem cells. Sci Rep 2: 362 .

Steinberg GR, Kemp BE (2009) AMPK in health and disease. Physiol Rev 89: 1025-1078.

Tanaka T, Munshi A, Brooks C, Liu J, Hobbs ML, Meyn RE (2008) Gefitinib radiosensitizes non-small cell lung cancer cells by suppressing cellular DNA repair capacity. Clin Cancer Res 14: 1266-1273.

Taubes G (2012) Cancer research. Cancer prevention with a diabetes pill? Science 335: 29.

Tsakiridis T, Cutz JC, Singh G, Hirte H, Okawara G, Corbett T, Sur R, Cai W, Whelan T, Wright JR (2008) Association of phosphorylated epidermal growth factor receptor with survival in patients with locally advanced nonsmall cell lung cancer treated with radiotherapy. J Thorac Oncol 3: 716-722.

Vazquez-Martin A, Oliveras-Ferraros C, Cufi S, Martin-Castillo B, Menendez JA (2011) Metformin activates an ataxia telangiectasia mutated (ATM)/ Chk2-regulated DNA damage-like response. Cell Cycle 10: 1499-1501.

Vazquez-Martin A, Oliveras-Ferraros C, Del Barco S, Martin-Castillo B, Menendez JA (2009) If mammalian target of metformin indirectly is mammalian target of rapamycin, then the insulin-like growth factor-1 receptor axis will audit the efficacy of metformin in cancer clinical trials. $J$ Clin Oncol 27(33): e207-e209.

Zakikhani M, Blouin MJ, Piura E, Pollak MN (2010) Metformin and rapamycin have distinct effects on the AKT pathway and proliferation in breast cancer cells. Breast Cancer Res Treat 123: 271-279.

This work is published under the standard license to publish agreement. After 12 months the work will become freely available and the license terms will switch to a Creative Commons AttributionNonCommercial-Share Alike 3.0 Unported License.

Supplementary Information accompanies this paper on British Journal of Cancer website (http://www.nature.com/bjc) 